21. Lovchikov A. V. Mine-tectonic rock bursts at the Lovozersky rare-metal deposit. Vestnik of MSTU. 2008. Vol. 11, No. 3. pp. 385-392.

22. Kosuhin N. N. Predicting rock burst hazard of a rock mass when mining in the zones of tectonic fault influence: thesis of inauguration of Dissertation ... of Candidate of Engineering Sciences. - Saint-Petersburg : NMU Gornyi, 2016. - 22 p.

23. Batugin A. S. To the mechanism of manifestation of fault displacement movement in tectonic rock bursts. Collection of studies. Saint-Petersburg : VNIMI, 1994. pp. 157-160.

24. Filippov V. N. Improving the efficiency of carrying out and supporting developing and face entries in the zones tectonic faults at iron-ore deposits : thesis of inauguration of Dissertation ... of Candidate of Engineering Sciences. - Novosibirsk : SB RAS, 2011. - 23 p.

25. Applied statistics reference. Ed. by E. Lloyd, U. Lederman
Moscow : Finansy i stilistika, 1990. 526 p.

26. David W. S. On Optimal and Data-Based Histograms. Biometrika. 1979. Vol. 66, No. 3. pp. 605-610.

27. Freedman D., Diaconis P. On this histogram as a density estimator: L2 theory. Zeitschrift fur wahrscheinlichkeitstheorie und verwandte gebiete. 1981. Vol. 57. pp. 453-476.

28. Ayvazyan S. A, Buhshtaber V. M., Enyukov I. S., Meshalkin L. D. Applied statistics: classification and dimensionality decreasing. Reference book. Moscow : Finansy i stilistika, 1989. 607 p.

29. Rodionov D. A., Kogan R. I., Golubeva V. A., Smirnov B. I. Sirotinskaya S. V. Reference on mathematical methods in geology. Moscow : Nedra, 1978. 335 p.

30. Kiselev V. A., Tsvetkova I. V. Creating zoning maps by means of GIS based on the determination of the multivariable dataset statistical homogeneity. Gornyi Zhurnal. 2008. No. 5. pp. 42-50. EM

UDC 621.039 .75

A. D. GVISHIANI ${ }^{1,2}$, Chief Scientist of Geophysical Center RAS, Head of the Department, Academician of RAS, Doctor of Physical and Mathematical Sciences

V. N. TATARINOV ${ }^{1,2}$, Chief Researcher, Head of Laboratory, Chief Researcher, Doctor of Engineering Sciences

A. I. MANEVICH ${ }^{1,3}$, Researcher, Post-Graduate Student, a.manevich@gcras.ru

V. I. KAFTAN ${ }^{1}$, Chief Researcher, Doctor of Engineering Sciences

${ }^{1}$ Geophysical Center RAS, Moscow, Russia

${ }^{2}$ The Schmidt Institute of Physics of the Earth RAS, Moscow, Russia

${ }^{3}$ Mining Institute of NUST «MISiS», Moscow, Russia

\title{
GEODYNAMIC INTERPRETATION OF MODERN GEODYNAMIC MOVEMENTS IN THE SOUTHERN PART OF THE YENISEI RIDGE (IN APPLICATION TO THE PROBLEMS OF UNDERGROUND ISOLATION OF RADIOACTIVE WASTE)
}

\section{Introduction}

In 2019, at the Yenisei site (NizhneKansk massif, southern part of the Yenisei Ridge), the construction of an underground research laboratory (URL) began to substantiate the final decision on its geological suitability for the disposal of high-level radioactive waste (HLRW) [1, 2]. The international and Russian documents regulating the safety of handling HLRW state that the main barrier guaranteeing the safety of HLRW isolation for their entire period of radiobiological hazard (up to 100 thousand years) is the geological environment [3-5]. The modern international practice of choosing a site for HLRW disposal is based on a systematic analysis of a set of properties, phenomena and processes that affect the preservation of the insulating properties of the massif $[6,7]$.

The main danger is associated with large-scale geodynamic processes and phenomena $[8,9]$, the impact of which on a structurally disturbed massif leads to the
The results of geodynamic interpretation of the results of GNSS observations of presentday movements and modeling of the stress-strain state of the upper part of the Earth's crust in the area of the construction of an underground research laboratory to substantiate the safety of disposal of high-level long-lived radioactive waste in granite-gneiss rocks of the Nizhne-Kansk massif are presented.

The kinematic model of the area made it possible to assess the directions of block movements of large structural blocks. The greatest movement gradients were noted in the west, between the underground research laboratory site and the contact between the Siberian Platform and the West Siberian Plate along the Atamanovsky Fault. Local zones of stress concentration have been identified, in which destruction of the rock mass in the near-contour zone of underground workings is most likely.

Analysis of models and results of GNSS observations showed that the structural-tectonic block, in which the construction of the underground research laboratory is planned, is in relatively calm geodynamic conditions. Present-day movements determine the regime of sublatitudinal compression in azimuth close to 100-1100 at the underground research laboratory construction site. A systematic analysis of geological and geophysical data made it possible to obtain new knowledge about the kinematics and stress-strain state of the rock mass in the southern part of the Yenisei Ridge, necessary to ensure the geoecological safety of isolation of high-level radioactive waste in the granite-gneiss rocks of the Nizhne-Kansk massif.

Keywords: geodynamics, present-day crustal movements, GNSS, zoning, radioactive waste, Yenisei Ridge

DOI: 10.17580/em.2021.02.02 


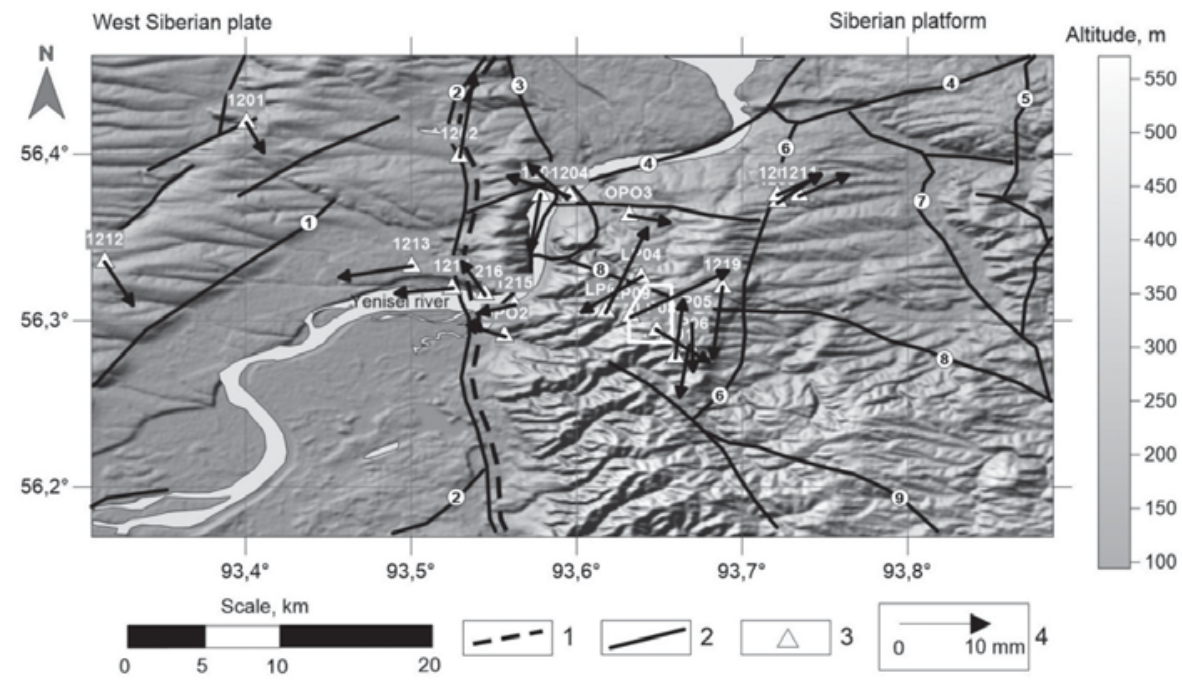

Fig. 1. Structural-tectonic scheme and present-day horizontal movements in the southern part of the Yenisei Ridge:

1 - the contact boundary between the Siberian Platform and the West Siberian Plate; 2 - large tectonic faults; 3 - GNSS points; 4 - MMEC velocity vectors of GNSS points, $\mathrm{mm} /$ year

formation of local zones of high-gradient stress fields and differentiated movements along the boundaries of structural blocks.

The Nizhne-Kansk massif is located in the zone of active orogeny, i.e. the process of its formation as a mountain structure has not yet been completed. Confirmation is the activity of the contact zone between the West Siberian Plate and the Siberian Platform along the Muratovsky and Atamanovsky faults [10-12]. In this regard, an urgent task is to develop a geodynamic model for the southern part of the Yenisei Ridge. Below we consider the results of interpretation of the observations results of modern movements of the Earth's crust (MMEC) using global navigation satellite systems (GNSS) and modeling of the stress-strain state (SSS), obtained within the framework of the Russian Science Foundation Project No. 18-17-00241.

\section{Methods and data}

To analyze the distribution of stress fields, we used the method of numerical calculation of the SSS of a block heterogeneous elastically isotropic rock mass, disturbed by a system of tectonic faults ${ }^{*}$, described in [9]. The upper part of the earth's crust is modeled by an elastically isotropic layer disturbed by subvertical tectonic faults; in the zone of their dynamic influence, the effective elastic modulus of the medium is taken to be $2-3$ orders of magnitude lower. The external tectonic stress field at the boundary is set based on geological data and GNSS measurements. Relationships between stresses and strains are assumed to be averaged over the layer thickness (generalized plane stress state). The calculations were performed with the following parameters: Young's modulus $\mathrm{E}=5 \cdot 10^{4} \mathrm{MPa}$, effective elastic modulus of the fault zones $\mathrm{E}_{\text {eff }}=5 \cdot 10^{2} \mathrm{MPa}$, Poisson's ratio $\mathrm{v}=0.25$. In modeling, we used a structural-tectonic scheme compiled based on research materials [12]. The compression axis orientation is assumed to be $\sigma_{\max }=-30 \mathrm{MPa}$ and $\sigma_{\min }=10 \mathrm{MPa}$.

To build a geodynamic model, GNSS data for the period from 2010 to 2019 were used. Observations of horizontal MMEC velocities for the area were started in 2010, then in 20122016 and in 2018-2019 they were continued at the geodynamic test site, created by the specialists of $\mathrm{OOO}$ Geolcom and the GC RAS, consisting of 30 GNSS points. A total of 9 epochs of measurements were carried out, the results are presented in $[12,13]$. Root-mean-square errors in determining the coordinates of GNSS points in plan and in height were 3-4 $\mathrm{mm}$ and 5-7 mm, respectively. Figure 1 shows the location of points for the 2019 epoch and a diagram of the main tectonic faults.

Numbers in circles in Fig. 1-4 the main tectonic faults are marked: 1 - the First Krasnoyarsk Fault; 2 - Muratovsky Fault; 3 - Atamanovsky Fault; 4 - Kansk-Atamanovsky Fault; 5 - Malotelsky Fault; 6 - Pravoberezhny Fault; 7 - Bolshetelsky Fault; 8 - Shumikhinsky Fault; 9 - Baikal Fault. The URL construction site is shown as a white rectangle.

To predict the stability of objects with a long service life, it is not the absolute offset values that are essential, but the strain velocities [14]. For the deformation analysis, the strain components were calculated:

$$
\left[T_{i j}\right]=\left[\begin{array}{ll}
\varepsilon_{11} & \varepsilon_{12} \\
\varepsilon_{21} & \varepsilon_{22}
\end{array}\right],
$$

which are defined as partial derivatives of coordinates offsets:

$$
\varepsilon_{11}=\frac{\partial u}{\partial y}, \varepsilon_{22}=\frac{\partial u}{\partial x}, \varepsilon_{12}=\varepsilon_{21}=\frac{1}{2}\left(\frac{\partial u}{\partial y}+\frac{\partial u}{\partial x}\right) \text {. }
$$

The following invariant characteristics were calculated to study the spatiotemporal distribution of horizontal strains.

1. The main deformations $E_{1}, E_{2}$ :

$$
E_{1,2}=\frac{\varepsilon_{11}+\varepsilon_{22}}{2} \pm \sqrt{\frac{\left(\varepsilon_{11}-\varepsilon_{22}\right)^{2}+\left(\varepsilon_{12}+\varepsilon_{21}\right)^{2}}{4}} .
$$

2. Full shear strain:

$$
\gamma_{m}=\sqrt{\left(\varepsilon_{11}-\varepsilon_{22}\right)^{2}+\left(\varepsilon_{12}+\varepsilon_{21}\right)^{2}} \text {. }
$$

3. Strain dilatation:

$$
\Delta=\varepsilon_{11}+\varepsilon_{22} \text {. }
$$

\section{Results of geodynamic interpretation}

At the final stage, a geodynamic interpretation of GNSS observations was performed in combination with the results of mathematical modeling of SSS, taking into account the experience of similar studies abroad, including in foreign

* The method and algorithm were developed by V. N. Morozov and I. Yu. Kolesnikov. 


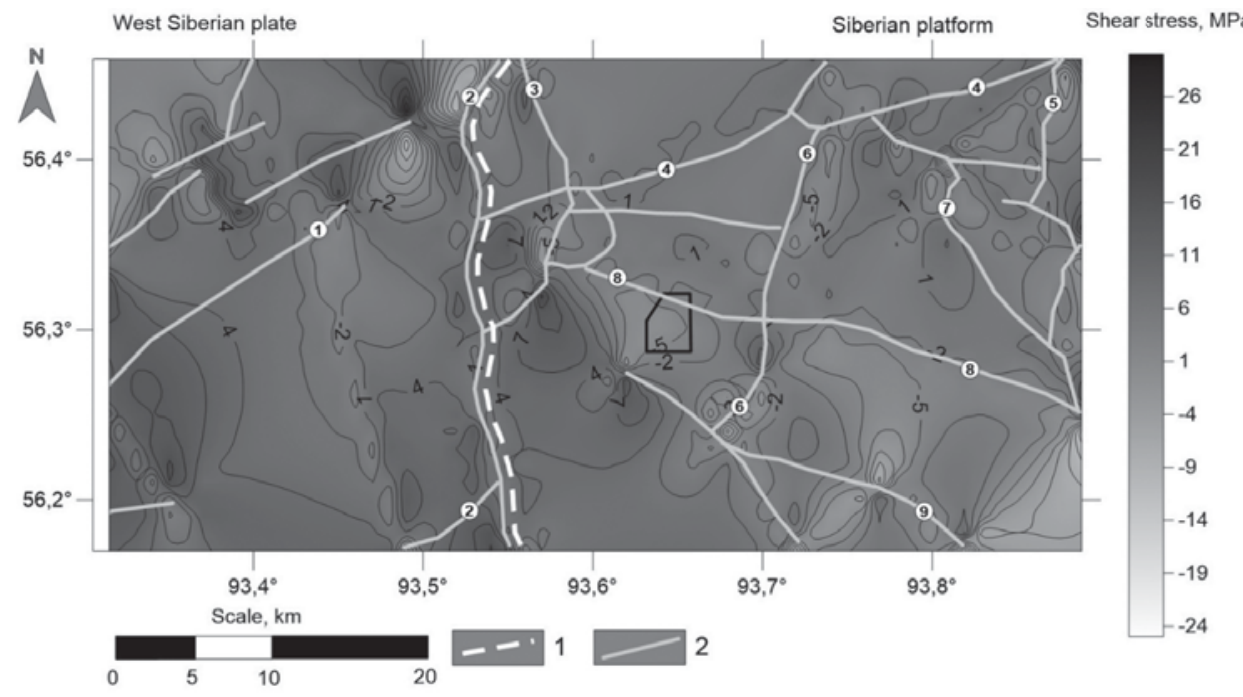

Fig. 2. Shear stresses $\tau_{x y}$ in the area of the Nizhne-Kansk massif according to the results of the numerical modeling:

1 - the contact boundary between the Siberian Platform and the West Siberian Plate; 2 - large local tectonic faults

underground laboratories $[15,16]$. The following are the main conclusions.

SSS modeling. Based on the results of numerical modeling of SSS in the study area, the stress components $\sigma_{x x}, \sigma_{y y}$ $\tau_{x y}$ were calculated and local stress concentration zones with values approximately 2 times higher than the development of hazardous seismic and deformation processes were identified (Fig. 2). A sumeridionally oriented anomalous zone of high stresses $\left(s_{i}>50 \mathrm{MPa}\right)$ was obtained west of the contact boundary between the West Siberian Plate and the Siberian Platform. Most likely, it is due to the absence of faults in the left-bank zone, which contribute to the relaxation of accumulated tectonic stresses. In general, this does not contradict the geodynamic model of the evolution of the Yenisei Ridge by acad. V. A. Vernikovsky [17]. Within the Siberian Platform, there are local areas of stress concentration confined to fault closures and areas of low values of $s_{i}$ in the extent of faults.

The Yenisei section is in the area of relatively low values of shear stresses (see Fig. 2). However, to the south is the end of the Baikal Fault and a zone of increased values of $\tau_{x y}>7$ $\mathrm{MPa}$ is formed, to the northwest of it is another zone associated with the closure of the Shumikhinsky Fault. Theoretically, these zones can interact and cause negative geomechanical processes in the marginal part of the URL workings.

MMEC monitoring. The MMEC velocity map was analyzed in conjunction with high-precision leveling data and geological surveys. Figure 3 shows the distribution of velocities and orientation axes of the main deformations $S_{h \max }$ and $S_{h \min }$. Tensile deformations predominate within the Atamanovsky spur of the Yenisei Ridge, which correlates with the tendency to rise during the Quaternary period. Submeridional compression deformations predominate within the West Siberian Plate, probably due to negative vertical movements.

Blocks VI, VIII, IX, X, XI, bounded by the Kansk-Atamanovsky (from the north) and Muratovsky (from the west) faults have the velocity of about $3.5 \mathrm{~mm} /$ year. In the wings of the Pravoberezhny Fault (№ 6 in Fig. 4), block shear movements create a "step-like" structure. The maximum gradients of horizontal movements are obtained from the contact between blocks VIII and IX. The boundary of the direction change from the sublatitudinal to the submeridional coincides with the Shumikhinsky Fault (№ 8 in Fig. 4), which directly crosses the URL construction site. This section is located at a distance of $2-3 \mathrm{~km}$ from

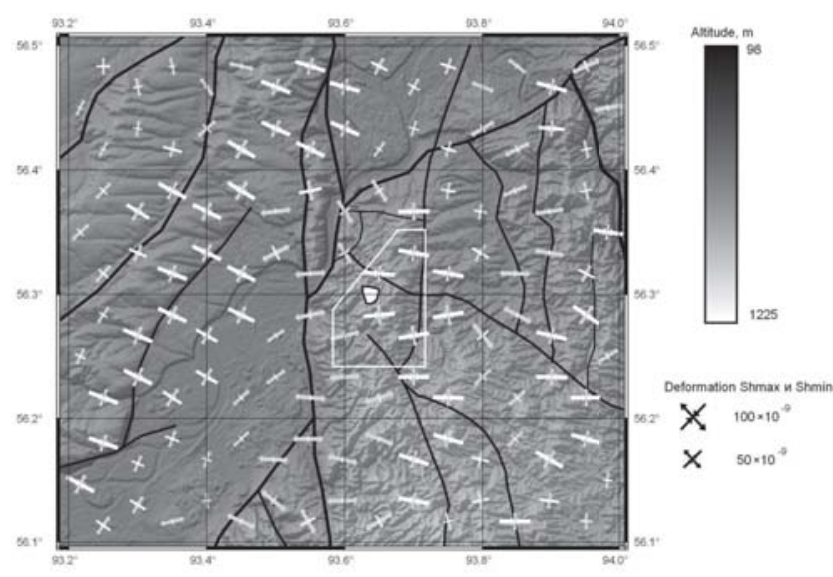

Fig. 3. Movement velocities and orientation axes of the main deformations

the contact zone between the Siberian Platform and the West Siberian Plate and is under its influence. The convergence rate of these structures in the southern part of the Yenisei Ridge can be estimated at 2-4 mm/year [13]. Probably, this is due to the rise of the Atamanovsky spur and the movement of block VII to the west, and block XIII - to the east.

Three blocks are distinguished in the western part, with maximum velocities of about $2-3 \mathrm{~mm} / \mathrm{yr}$ (see Fig. 4). The MMEC velocities confirm the tectonic activity of the Muratovsky, Atamanovsky, Kansk-Atamanovsky, Pravoberezhny and Shumikhinsky faults. Movements in the central and northern parts of the region (blocks IV and V) change directions from sublatitudinal to submeridional, which indicates a possible shear character of movements along the Muratovsky and Atamanovsky faults. This area turned out to be the most mobile [12].

Present-day movements generally determine the regime of sublatitudinal compression in azimuth close to 100-1100. Within the blocks, relatively low velocities of the MMEC were obtained, which indicates a stable geodynamic regime of the URL site.

An analysis of the dynamics of change in baseline lengths in time showed that in 2013-2014 there was an activation of the geodynamic regime of the region, which manifested itself in a sharp change in baseline lengths and a change in the sign of compression and extension deformations on the right-bank 


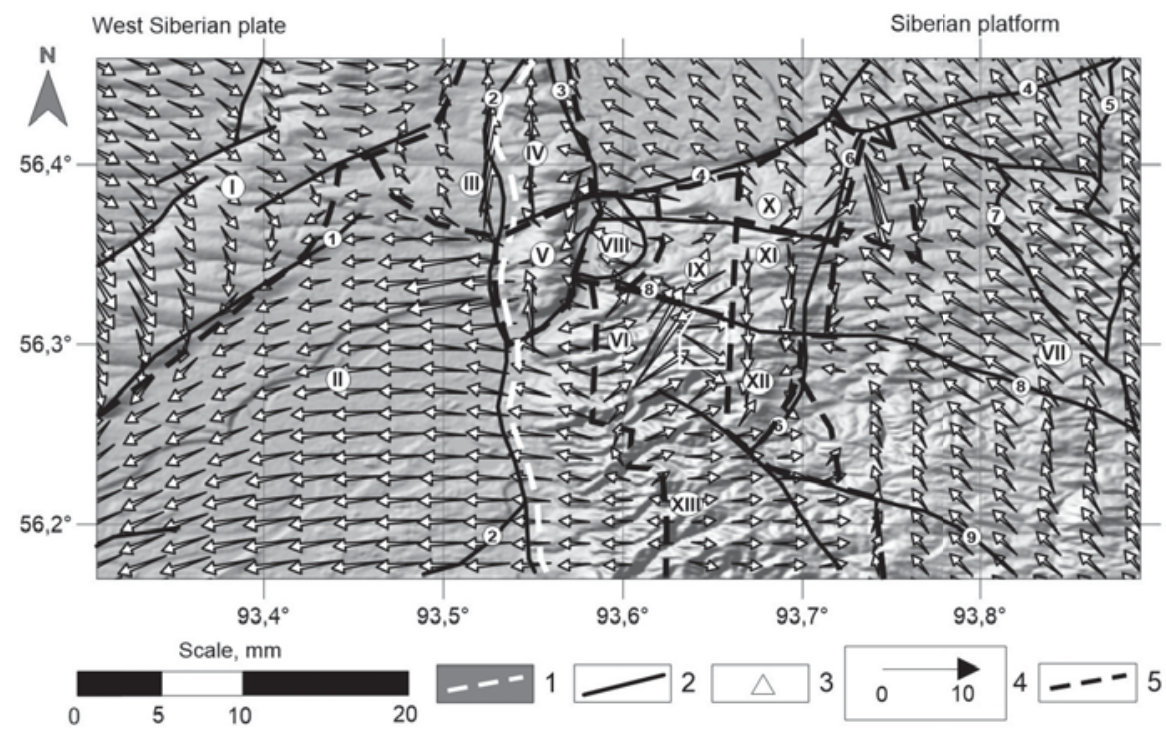

Fig. 4. Velocity field of presentday horizontal movements of the earth's crust in the southern part of the Yenisei Ridge:

1 - the contact boundary between the Siberian Platform and the West Siberian Plate; 2-large tectonic faults; 3 - GNSS points; 4 - MMEC velocity vectors of GNSS points, mm/year; 5 - active geodynamic zones corresponding to the boundaries of structural blocks with different kinematic characteristics. Latin numbers denote tectonic blocks distinguished according to GNSS observations.

and left-bank parts of the Yenisei River. Annual changes reached 15-20 $\mathrm{mm}$ in some cases [13]. With an increase in the observation time due to the effect of cyclicity, they decrease. When forecasting, this effect must be taken into account. Over an 8-year observation period, only in rare cases do the change velocities in baseline lengths exceed $5 \mathrm{~mm}$ /year in absolute value. Basically they are in the range of $1-3 \mathrm{~mm} / \mathrm{year}$

\section{Conclusions}

A map of the horizontal MMEC velocities in the southern part of the Yenisei Ridge was drawn. The boundaries of large structural blocks with different kinematic characteristics (direction of movement, absolute values of velocities) were established. For the central and eastern parts of the region, the greatest variability in the distribution of vectors (up to a change of 180 degrees) was noted at velocities of more than $4 \mathrm{~mm} /$ year. Most likely, this is a consequence of the interaction of the largest structures the Siberian Platform and the West Siberian Plate.

Local stress concentration zones were identified, in which the destruction of the rock mass is most likely as a result of tectonic creep, the formation of new faults or seismic events. A thick submeridionally elongated area of high stress intensity values (more than $30 \mathrm{MPa}$ ) was established in the west of the boundary between the West Siberian Plate and the Siberian Platform.

The resulting model is in good agreement with the results of structural-geological and geodynamic studies in the area. Comparing the calculated values of dilatation with the criteria given in the literature for geodynamic active zones ( $D= \pm 5 \cdot 10^{-4}-5 \cdot 10^{-5}$ per year) $[18,19]$, it can be argued that the location area of the Yeniseisky site is characterized by relatively low deformation velocities of the earth's crust.

A kinematic MMEC model was constructed, which makes it possible to estimate the directions of block movements. Movements on the URL site and the structural block containing it are more homogeneous and uniform than along its boundaries. The greatest movement gradients occur in the western part of the block located between the site and the contact between the Siberian Platform and the West Siberian Plate along the Atamanovsky Fault.

Thus, the geodynamic interpretation and systematic analysis of geological and geophysical data made it possible to obtain new knowledge about the kinematics and stress-strain state of the southern part of the Yenisei Ridge, which is necessary to ensure the geoecological safety of underground isolation of highlevel radioactive waste in the rocks of the Nizhne-Kansk massif.

\section{Aknowledgements}

This work was funded by the Russian Science Foundation (project No. 18-17-00241).

References

1. Dorofeev A. N., Bolshov L. A., Linge I. I., Utkin S. S., Saveleva E. A. Strategic master plan for R\&D demonstrating the safety of construction, operation and closure of a deep geological disposal facility for radioactive waste. Radioaktivnye otkhody. 2017. No. 1. pp. 33-42.

2. Abalkina I. L., Bolshov L. A., Kapyrin I. V., Linge I. I., Saveleva E. A. et al. Radioactive waste and spent nuclear fuel deep geological disposal long-term safety assessment for 10000 years and over: methodology and the current state. Preprint IBRAE-2019-03. Moscow : Nuclear Safety Institute, 2019. 40 p.

3. Tsebakovskaya N. S., Utkin S. S., Kapyrin I. V. H. et al. Review of foreign practices of SNF and RW disposal. Eds. by I. I. Linge, Yu. D. Polyakov. Moscow : Komtekhprint, 2015. 208 p.

4. Laverov N. P., Velichkin V. I., Kochkin B. T., Malkovsky V. I., Petrov V. A. et al. Safety assessment concept for repositories of spent nuclear materials in crystalline rocks. Geoecologiya. 2010. No. 3. pp. 195-206.

5. Melnikov N. N., Konukhin V. P., Naumov V. A., Gusak S. A. Research substantiation of constructive-layout solutions of underground storehouse for spent nuclear fuel. Gornyi Zhurnal. 2010. No. 9. pp. 55-57.

6. Results of Monitoring at Olkiluoto in 2017. Rock Mechanics. Working Report 2018-27. Posiva OY. June 2018. 126 p.

7. Haapalehto S., Malm M., Kaisko O., Saaranen V. Results of monitoring at Olkiluoto in 2017. Rock mechanics. Finland : Posiva OY, Eurajoki, 2018. 126 p.

8. Nesmeyanov S. A. Engineering geotectonics. Moscow : Nauka, 2004. 780 p.

9. Anderson E. B. et al. Underground isolation of radioactive waste. Moscow : Gornaya kniga, 2011. 592 p. 
10. Bachmanov D. M., Kozhurin A. I., Trifonov V. G. The active faults of Eurasia database. Geodynamics \& Tectonophysics. 2017. Vol. 8(4). p. 711-736.

11. Lobatskaya R. M. Neotectonic fault-block structure of junction of Siberian Platform and West Siberian Plate. Geologiya i Geofizika. 2005. Vol. 46(2). p. 141-150.

12. Gvishiani A. D., Tatarinov V. N., Kaftan V. I., Manevich A. I., Dzeboev B. A., Losev I. V. The velocities of modern horizontal movements of Earth crust in the South sector of Yenisei Ridge according to GNSS observations. Doklady Earth Sciences. 2020. Vol. 493(1). p. 73-77. DOI: 10.1134/S1028334X20070077

13. Tatarinov V. N., Morozov V. N., Kaftan A. I., Manevich A. I. Modern geodynamics of the southern of the Yenisei Ridge derived from the results of satellite observations. Geophizicheskie issledovaniya. 2018. Vol. 19(4). pp. 64-79.

14. Manevich A. I., Tatarinov V. N., Kolikov K. S. Detection of crustal deformation anomalies with regard to spatial scale effect. Eurasian Mining. 2019. No. 2. pp. 19-22. DOI: 10.17580/ em.2019.02.04

15. Wright T. J., Lou Y., Zhang R., Zhang W., Shi C., Huang J., Na Wei. Crustal Deformation in the India-Eurasia Collision Zone
From 25 Years of GPS Measurements. 2017. Journal of Geophysical Research: Solid Earth. 2017. Vol. 122. pp. 9290-9312.

16. Roštínský P., Pospíšil L., Švábenský O., Kašing M., Nováková E. Risk faults in stable crust of the eastern Bohemian Massif identified by integrating GNSS, levelling, geological, geomorphological and geophysical data. Tectonophysics. 2020. Vol. 785. 228427.

17. Vernikovsky V. A., Metelkin D. V., Vernikovskaya A. E., Matushkin N. Y., Kadilnikov P. I. et al. Neoproterozoic tectonic structure of the Yenisei ridge and formation of the western margin of the Siberian craton based on new geological, paleomagnetic, and geochronological data. Russian Geology and Geophysics. 2016. Vol. 57(1). pp. 47-68.

18. Kuzmin Y. O. Recent geodynamics of dangerous faults. Izvestiya. Physics of the Solid Earth. 2016. Vol. 52, No. 5. pp. 709-722.

19. Morozov V. N., Tatarinov V. N., Manevich A. I., Losev I. V. Analogy method to determine the stress-strain state of structuraltectonic blocks of the Earth's crust for the disposal of radioactive waste. Russian Journal of Earth Sciences. 2019. Vol. 19. DOI: $10.2205 / 2019 E S 000687$ 테

Yu. P. GALCHENKO ${ }^{1}$, Expert, Doctor of Engineering Sciences, Professor

V. A. EREMENKO ${ }^{7}$, Director of Research Center for Applied Geomechanics and Convergent Mining Technologies, Doctor of Engineering Sciences, Professor of the Russian Academy of Sciences, prof.eremenko@gmail.com

N. G. VYSOTIN ${ }^{1}$, Senior Lecturer

M. A. KOSYREVA ${ }^{1}$, Post-Graduate Student

${ }^{1}$ NUST MISIS College of Mining, Moscow, Russia

\section{JUSTIFICATION OF FUNCTIONAL ORGANIZATION AND CONTENTS OF MODELING CLUSTER CONCEPT FOR GEOMECHANICAL RESEARCH OF CONVERGENT MINING TECHNOLOGIES*}

\section{General provisions}

Regarding the impact on the environment (or lithosphere, in our case), the key difference of the nature-like convergent mining technologies from the conventional geotechnologies is the indispensable preventive negotiation with geomechanical after-effects of mining-induced damage. Modeling should always take this fact into account and should assume the time effect as the advanced implementation of ground control in the course of stoping.

The governing criteria and constants of modeling a technology cluster are selected from the dynamic similarity law. In this case, the modeling reveals the stress-strain behavior of a mining system and its components subject to the breakage and drawing conditions
The new scientific school on the nature-like convergent mining technologies, which assume preventive negotiation of geomechanical consequences of mining-induced damage in the lithosphere, requires adjustment of the conventional modeling methods using the factor of time. In the framework of the main theories of similarity, the comparative studies of different model material composition are carried out, and the formula of solidifying mixtures is justified for equivalent materials for modeling joint loading of manmade and natural components of geotechnical systems. An original procedure is proposed for the construction of block models by means of gluing, such that the unit block sizes are determined in terms of sizes blocks generated by joint systems, and the number and location of gluing points are selected as function of condition of healed joints. The new procedure efficiency is checked by the method of calibration and comparison of the modeling data with the quantitative assessments of the real-life rock masses. For different mining systems, the interpolating functions of the influence factor are plotted to image the rock mass stability categories. The new instrumentation is created for the integrated test workbenches, which provides integrated patterns of strength, deformation and acoustic characteristics of physical models of the proposed convergent geotechnical systems, the obtained values of the strength and deformation characteristics of the physical models made it possible to calibrated the relevant numerical models based on the retrospective analysis of deformation process evolution. It has been proved for the first time that the values of microstrains can be used as the indicators of the secondary stress field in the structure of anthropogenically altered subsoil as an independent object in the lithosphere.

Keywords: Convergent mining technologies, geomechanics, secondary stress field, similarity theory, modeling, clusters, procedure, model material, calibration, experiment

DOI: $10.17580 /$ em.2021.02.03

*The study was supported by the Russian Science Foundation, Project No. 19-17-00034. 